\title{
Violência contra mulher: contribuições da enfermagem junto ao público evangélico
}

\author{
Violence against women: nursing contributions to the \\ evangelical public
}

\begin{abstract}
Euriane Castro Costa', Vera Lúcia de Azevedo Lima², Victor Assis Pereira da Paixão', Raine Marques da Costa'

'Curso de Enfermagem, Faculdade de Enfermagem, Instituto de Ciências da Saúde, Universidade Federal do Pará, Belém (PA), Brasil.

${ }^{2}$ Programa de Pós-graduação em Enfermagem, Faculdade de Enfermagem, Instituto de Ciências da Saúde, Universidade Federal do Pará, Belém (PA), Brasil.
\end{abstract}

\section{RESUMO}

Contextualização: O Programa de Extensão da Faculdade de Enfermagem intitulado Empoderamento e Fortalecimento da Mulher Amazônica frente à Violência Doméstica e Familiar/PROEX/UFPA desenvolvem atividades de informar, sensibilizar, esclarecer e instrumentalizar as mulheres sobre as políticas públicas específicas que podem proporcionar o empoderamento e o fortalecimento frente à violência familiar vivenciada no âmbito das relações do dia a dia. Descrição da experiência: Trata-se de um relato de experiência, com base em uma atividade educativa vinculada ao Programa, realizada com um grupo de 50 pessoas de uma igreja evangélica no bairro do Tapanã, em Belém-PA, em janeiro de 2017. As atividades foram desenvolvidas em 3 etapas. 1- Apresentação do programa de extensão e dinâmica quebra-gelo e teatro; 2- Debate intitulado "não violente, nem sofra violência"; 3-Distribuição de folder "Violência Contra à Mulher esse mal tem que acabar". A ação possibilitou a construção do conhecimento crítico e reflexivo em uma temática pouco abordada e discutida no meio evangélico. Considerações finais: A religião é condescendente com a reprodução e manutenção da violência contra a mulher no momento em que se omite, tornando-se cúmplice da cultura do silêncio, da falta de denúncia. O trabalho de informação e prevenção é de extrema importância para que o índice de violência contra mulher no meio cristão diminua e que gere denúncia por meio de suas instituições e membros.

Recebido: Ago. 16, 2017 Aceito: Fev. 27, 2018

\section{COMO CITAR ESTE ARTIGO}

Costa EC, Lima VLA, Paixão VAP, Costa RM. Violência contra mulher: contribuições da enfermagem junto ao público evangélico. Interdisciplinary Journal of Health Education. 2017 Jul-Dez;2(2):110-114. https://doi. org/10.4322/ijhe.2017.003

\section{CORRESPONDÊNCIA}

Euriane Castro Costa

Faculdade de Enfermagem, Instituto de Ciências da Saúde, Universidade Federal do ParáCidade Universitária Prof. José da Silveira Neto Campus Profissional II, Complexo Saúde, Rua Augusto Corrêa, 01, Guamá, CEP 66075-110, Belém (PA), Brasi

eurianecastro19@gmail.com

FONTE DE FINANCIAMENTO

Pró-reitoria de extensão (PROEX).

\section{CONFLITO DE INTERESSE}

Não houve conflito de interesses.

O estudo foi realizado em Belém (PA), Brasil.

Todos os autores leram e aprovam a versão final submetida ao Interdisciplinary Journal of Health Education (IJHE).
PALAVRAS-CHAVE: Violência. Mulher. Religião. Enfermagem. Educação.

\section{ABSTRACT}

Background: the extension Program titled Empowerment and strengthening of the domestic violence front Amazon Woman and Familiar/PROEX/UFPA develop activities to inform, raise awareness, clarify and exploit women about the specific public policies that can provide the empowerment and strengthening front family violence experienced in the context of day-to-day relations. Description of the experience: the case studies, based on an activity linked to the educational program, performed with a group of 50 young people of an Evangelical Church in the neighborhood of Tapanã, in Belem-PA in January 2017. The activities were developed in 3 stages. 1-presentation of the extension program and ice-breaking and dynamic Theatre; 2-Debate entitled "not violent, nor suffer violence"; 3-distribution of folder "violence against the woman that evil must end". The action made possible the construction of critical knowledge and reflective in a subject little discussed and discussed in the middle. Final considerations: it was found that nursing must participate and implement educational activities in the community providing information to relevant themes and great social and public health impact of violence against women, which will help you in your training as future nurses to deal with the problem, as well as the interaction, discussion and reflection of the evangelical community on the topic permeated by taboos and prejudices.

KEYWORDS: Violence. Women. Religion. Nursing. Education. 


\section{Contextualização}

O Programa de Extensão da Faculdade de Enfermagem da Universidade Federal do Pará (UFPA), intitulado Empoderamento e Fortalecimento da Mulher Amazônica frente à Violência Doméstica e Familiar desenvolve atividades de informar, sensibilizar, esclarecer e instrumentalizar as mulheres sobre as políticas públicas específicas que podem proporcionar o empoderamento e o fortalecimento frente à violência familiar vivenciada no âmbito das relações do dia a dia.

O conceito de violência é muito amplo e a palavra deriva do latim e sua origem está relacionada com o termo "violação". A violência contra a mulher é considerado qualquer ato ou conduta baseada no gênero que possa causar morte, dano, sofrimento físico, sexual ou psicológico à mulher, que podem levar à depressão, a morte e mesmo ao suicídio ${ }^{1}$.

O fenômeno da violência contra a mulher é reconhecida como um problema de saúde pública e violação dos direitos humanos em todo o mundo. O Art. 30 da lei 11.340, é de competência da equipe multidisciplinar desenvolver trabalhos de orientação, encaminhamento, prevenção e outras medidas².

Realizar as ações educativas de prevenção em comunidades e instituições deve perpassar os princípios do diálogo em que ocorrem combinações de experiências de aprendizagem. E as ações do projeto proporcionam essa interação, a construção do conhecimento entre o saber técnico e o saber popular entendendo que ambos possuem saberes diferentes e não hierarquizados ${ }^{3}$.

Abordar a temática junto às igrejas evangélicas pode abrir o diálogo para que outras tradições religiosas examinem a relação entre sua fé e o trágico fenômeno da violência.

A religião foi, historicamente, a ferramenta mais ampla e efetiva da legitimação. A presença da religião na origem de toda sociedade humana é fundamental, a mesma serve como meio de instrução para os homens. A religião, basicamente está popularmente associada com a paz, com amor, o que dificulta a percepção potencial de violência embutidos em seu discurso e em sua prática, sobretudo em relação às mulheres ${ }^{4}$.

Sobre a violência doméstica perpetrada contra as mulheres evangélicas no Brasil há poucos estudos, mas os que existem afirmam, ser atribuída à forte presença da cultura patriarcal e de sujeição em nossa sociedade, havendo estreita relação com a religião, o que de certa forma, contribui para a prática de vários tipos de violência sofrida por muitas mulheres ${ }^{4}$. Os tabus religiosos, muitas vezes colaboram para manter a mulher que sofre violência em seu relacionamento. A falta de preparo teológico para lidar com situações de violência, também pode contribui e alimentar a ideia de que o lar é um lugar seguro e que não ocorre ou não deveria ocorrer tal fato ${ }^{4-6}$. Infelizmente as famílias com experiências religiosas também podem ser afetadas com essa problemática.

Estudo realizado em Recife com 82 líderes de igrejas evangélicas ficou evidenciado a preocupação com as situações de violência, que não raramente surgem nas famílias que frequentam as igrejas, e a necessidade que muitos afirmaram de aprender formas práticas de enfrentar esta violência a partir de uma perspectiva bíblica e pastoral ${ }^{7}$. Análise realizada na casa Sofia, projeto social em São Bernardo do Campo que trabalha no apoio as mulheres que sofre violência revela que $40 \%$ declaravam-se evangélicas ${ }^{6}$. Um estudo realizado em Belém do Pará com 300 mulheres vítimas de violências atendidas na Delegacia Especializada de Atendimento à Mulher (DEAM), no período de 01 de julho a 31 de dezembro de 2012, aponta que 27,00\% declaravam-se evangélicas, ou seja, a violência ocorre em todos os âmbitos sociais ${ }^{8}$. Segundo o relatório sobre igrejas e abuso doméstico Domestic violence and the Church research report de 2016, nos Estados Unidos a pesquisa com 1000 líderes religiosos protestantes, 47\% afirmam não estão cientes de casos de violências domesticas em suas congregações e $37 \%$ diz que um membro já foi vítima. E muitos deles não sabem como agir diante da situação9 
As igrejas querem ajudar as vítimas, mas nem sempre são efetivas em fazer, pois não sabem por onde começar. Apenas $52 \%$ tem um plano para ajudar vítimas. As igrejas pouco discutem sobre o assunto, $4 \mathrm{em} 10$ disseram que raramente discutem ou nunca abordaram e $22 \%$ discutem uma vez por ano 9 . Surge assim a importância de debater a violência com o público evangélico, onde a temática quase não é abordada, devido a tabus e dogmas.

\section{Descrição da experiência}

A atividade educativa realizada com um grupo de 50 pessoas de uma igreja evangélica em no bairro do Tapanã em Belém-PA em março de 2016. Os adolescentes e jovens eram do sexo feminino e masculino, na faixa etária entre 14 e 35 anos, predominantemente do ensino médio, nível superior completo e incompleto. A escolha pelo público foi motivada pelo importante trabalho de discussão de temas sociais relevantes que a instituição religiosa exerce na comunidade e também por membros do programa frequentar a congregação oferecendo maior abertura para realização da ação educativa, o que possibilita o fortalecimento e empoderamento de sujeito.

As atividades foram desenvolvidas em 3 etapas. 1- Apresentação do programa de extensão e dinâmica (quebra-gelo); 2- Debate intitulado "não violente, nem sofra violência"; 3-Distribuição de folder "Violência Contra a Mulher esse mal tem que acabar".

No primeiro momento, foi apresentado o programa de extensão. Em seguida, realizou-se dinâmica quebra gelo, na qual foram distribuídos aleatoriamente papéis com os tipos de violência, os participantes deveriam ler em voz alta a palavra sorteada, dizer se conheciam o significado ou exemplificá-la, logo após um grupo de teatro representava uma cena relacionada à violência citada.

Na segunda etapa, iniciou-se o debate intitulado "não violente, nem sofra violência", a partir de material produzido pelos acadêmicos no programa Microsoft Power Point 2010, e pequenos vídeos. Foram tratados os seguintes tópicos: O que éa violência contra a mulher; quais os tipos de violências; o ciclo da violência; abordagem da lei Maria da Penha; medidas protetivas; como identificar a mulher que sofre a violência; locais de apoio e como prevenir a violência contra a mulher. Onde ocorreu a contribuição dos participantes, através da abertura para os relatos de experiência, e esclarecimento de dúvidas. Na terceira etapa, foram distribuídos folder, e discutido os principais pontos do conteúdo que despertaram interesse do público.

\section{Resultados e impactos}

O tema foi bem aceito pelo público, que participou ativamente da dinâmica assim como no desenvolvimento da atividade. Ao utilizarmos o diálogo aberto percebeu-se a carência de informações quanto aos tipos de violência, pois sabiam caracterizar a violência física, psicológica e sexual, não referindo por vezes a violência patrimonial e moral como forma de agressão, exceto quando já vivenciada e/ou receberam informação para as tais. Desta forma foi necessário interferir e diferenciar cada tipo.

Sobre as medidas protetivas de urgência prevista na Lei Maria da Penha, os participantes relacionaram com proteção da mulher vítima de violência, porém não sabiam mencionar a abrangência da lei, salvo quando já exposta a violência ou conhecem casos próximo.

Foram levantadas questões sobre a violência no âmbito religioso muito relacionado à submissão e tradição patriarcal, abordando textos bíblicos, o que possibilitou a construção do conhecimento em uma temática pouco abordada e discutida no meio evangélico, como violência de gênero, que considera a mulher inferior ao homem. 
A abordagem espiritual da violência também foi relatada nas falas dos participantes. $\mathrm{O}$ fato de a religião trabalhar o espiritual algumas mulheres atribuem às violências sofridas, resultado da possessão demoníaca ${ }^{5,9}$. Desta forma a vítima legitima a agressão sofrida, pois o agressor não era seu companheiro, e sim o espírito que o dominava, levando-o a agir de forma violenta, o que por consequência torna o agressor em vítima.

Os valores da religião produzem vários fenômenos dando à mulher que sofre a violência um sentimento de culpa, pois em muitos casos, esta após passar a violência, revela tal sentimento ${ }^{5}$. A violência do autor é combatida com o poder de oração então a denúncia de seus companheiros agressores as induzem a sentirem-se culpadas, por entenderem que estão traindo sua igreja, os ensinos e seus lideres ${ }^{6}$.

A igreja pode ter condições de ajudar mulheres que vivem em situação de violência, implantando grupos de acompanhamento dessas mulheres e que trabalhem a conscientização e prevenção deste fenômeno ${ }^{6,7,9}$.

No Brasil, no enfrentamento das violências, o setor saúde, especialmente a Enfermagem tem um papel chave na identificação, notificação, tratamento e encaminhamento dos casos. As contribuições da enfermagem nesse contexto se dar pelo fato de trabalhar a prevenção por meio das ações educativas como estratégias para maior compreensão da violência, o que pode evitar com que as pessoas que obtiveram conhecimento da temática sejam um futuro paciente atendido como vítima de violência doméstica.

Por ser uma temática transversal, a violência é pouco abordada nas aulas do curso de Enfermagem, o que permite ao acadêmico participante do projeto uma formação com um olhar diferenciado quanto às pessoas que sofrem violência, o que refletirá no cuidado prestado como profissional.

Os resultados desta atividade foram positivos, pois oportunizou multiplicarmos as informações sobre a temática, políticas públicas e de enfrentamento, promovendo espaço de debate, conscientização. Induzindo a comunidade à reflexão, com objetivo de transformação social e autonomia dos sujeitos envolvidos, mostrando que a violência acontece independente da classe social ou do credo religioso e que todos podem atuar no combate e prevenção frente à violência contra a mulher.

\section{Considerações finais}

A religião é condescendente com a reprodução e manutenção da violência contra a mulher no momento em que se omite, tornando-se cúmplice da cultura do silêncio, da falta de denúncia. O trabalho de informação e prevenção é de extrema importância para que o índice de violência contra mulher no meio cristão diminua e que gere denúncia por meio de suas instituições e membros. Diante dos pontos abordados e contribuições com relatos vivenciados, apronta-se que as atividades realizadas pelo programa de extensão, possibilita, desenvolvem e proporciona ambientes de diálogos, apoio e compreensão, colaborando assim para o empoderamento e fortalecimento da comunidade no que se refere à violência contra a mulher.

\section{Referências}

1. CIDH: Comissão Interamericana de Direitos Humanos. Convenção Interamericana para prevenir, punir e erradicar a violência contra a mulher. "Convenção de Belém do Pará”. (Adotada em Belém do Pará, Brasil, em 9 de junho de 1994, no Vigésimo Quarto Período Ordinário de Sessões da Assembléia Geral). Washington: CIDH; 1994 [citado em 2017 julho 17]. Disponível em: http://www.cidh.org/Basicos/Portugues/m.Belem.do.Para.htm

2. Brasil. Lei $n^{\circ} 11.340$, de 7 de agosto de 2006. Cria mecanismos para coibir a violência doméstica e familiar contra a mulher, nos termos do $\S 80$ do art. 226 da Constituição Federal, da Convenção sobre a Eliminação de Todas as Formas de Discriminação contra as Mulheres e da Convenção Interamericana para Prevenir, Punir e Erradicar a Violência contra a Mulher; dispõe sobre a criação dos Juizados de Violência Doméstica e Familiar contra a Mulher; altera o Código de Processo Penal, o Código Penal e a Lei de Execução Penal; e dá outras providências. Diário Oficial da União [Internet], Brasília, 


\section{ijhe}

DF, 21 ago. 2006 [citado em 2017 julho 10]. Disponível em: http://www.planalto.gov.br/ccivil_03/_ato2004-2006/2006/lei/ 111340. htm

3. Silva CCL, Santos MC, Gomes CO. A educação em saúde como estímulo à cidadania: um relato de experiência. Rev Sau \& Transf Soc. 6(2):132-38, 2016.

4. Krob DB. A igreja e a violência doméstica contra as mulheres. In Anais do Congresso Internacional das Faculdades EST [Internet]; 2015; São Leopoldo. São Leopoldo (RS): Faculdades EST; 2014 [citado em 2018 Fev 17]. v. 2, p. $208-16$. Disponível em: http://anais.est.edu.br/index.php/congresso/article/viewfile/221/1987

5. Silva GV. A violência de gênero no Brasil e o gemido das mulheres evangélicas. Rev Teológica Discente da Metodista. 1(1), 131-42, 2013.

6. Vilhena VC. Resultado de uma pesquisa: uma analise da violência doméstica entre mulheres evangélicas. In Anais do Fazendo Gênero 9 Diáspora Diversidade Deslocamentos [Internet]; 2010 Ago 23-26; Florianópolis. Florianópolis (SC): UFSC; 2010 [citado em 2018 Jan 15]. Disponível em: http://www.gofazendogenero.ufsc.br/9/resources/anais1280156603ARQUIVO_ ValeriaCristinaVilhena.pdf

7. Carroll AS, Andrade S. Até quando? O cuidado pastoral em contexto de violência contra a mulher praticada por parceiro íntimo. Viçosa (MG): Ultimato; 2010.

8. Lima VL, Silva AF, Rosário EB, Sena LX, Gomes VR, Santos ACB. Necessidades humanas básicas comprometidas de mulheres vítimas de violência atendidas na delegacia especializada de atendimento a mulher. Rev. Eletrônica Gestão \& Saúde. 6(1), 366-78, 2015. http://dx.doi.org/10.18673/gs.v6i1.13741.

9. Miles A. Domestic violence and the Church research report [Internet]. LifeWay Research; 2017 [citado em 2018 Fev 20 ]. Disponível em: http://lifewayresearch.com/2017/02/20good-intentions-lack-of-plans-mark-church-response-to-domestic-violence/

\section{Contribuição dos autores}

Euriane Castro Costa contribuiu na concepção e desenvolvimento, supervisão, análise / interpretação, levantamento da literatura, redação, revisão crítica. Vera Lúcia de Azevedo Lima contribuiu na concepção e desenvolvimento, supervisão, revisão crítica. Raine Marques da Costa contribuiu na coleta e tratamento dos dados, levantamento da literatura, redação, revisão crítica. Victor Assis Pereira da Paixão contribuiu no desenho metodológico, análise / interpretação, levantamento da literatura. 